\title{
Stent thrombosis in early-generation drug-eluting stents versus newer-generation everolimus-eluting stent assorted by LVEF
}

\author{
Nick van Boven, ${ }^{1,2}$ Stephan Windecker, ${ }^{3}$ Victor A Umans, ${ }^{1}$ Ron T van Domburg, ${ }^{4}$ \\ Isabella Kardys, ${ }^{4}$ K Martijn Akkerhuis, ${ }^{4}$ Robbert-Jan van Geuns, ${ }^{4}$ Patrick W Serruys, ${ }^{4}$ \\ Michael Magro, ${ }^{4}$ Lorenz Räber, ${ }^{3}$ Eric Boersma ${ }^{4}$
}

\begin{abstract}
- Additional material is published online only. To view please visit the journal online (http://dx.doi.org/10.1136/ heartjnl-2014-305743).

'Department of Cardiology, Medical Centre Alkmaar, Alkmaar, The Netherlands ${ }^{2}$ Cardiovascular Research School (COEUR), Erasmus university, Rotterdam, The Netherlands ${ }^{3}$ Department of Cardiology, Bern University Hospital, Bern, Switzerland

${ }^{4}$ Erasmus MC, Rotterdam, The Netherlands
\end{abstract}

\section{Correspondence to} Professor Eric Boersma, Erasmus MC, Rotterdam, room Bd381 's Gravendijkwal 230, Rotterdam 3015 CE, The Netherlands; h.boersma@erasmusmc.nl

Received 20 February 2014 Revised 15 July 2014 Accepted 5 August 2014 Published Online First 27 August 2014

\begin{abstract}
Objective Everolimus drug-eluting stents (EES) are superior to early-generation drug-eluting stents (DES), releasing sirolimus (SES) or paclitaxel (PES) in preventing stent thrombosis (ST). Since an impaired LVEF seems to increase the risk of ST, we aimed to investigate the difference in outcome of patients with varying LVEF using EES versus early-generation DES.

Methods In a prospective cohort study, we compared the risk of ST in patients in three LVEF subgroups: normal (LVEF $>50 \%$ ), mildly impaired (LVEF $>40 \%$ and $\leq 50 \%$ ) and moderate-severely impaired (LVEF $\leq 40 \%)$. Within these various LVEF groups, we compared EES with SES and PES after adjustment for baseline differences.
\end{abstract}

Results We assessed a cohort of 5363 patients, with follow-up of up to 4 years and available LVEF. Overall definite ST occurred in 123 (2.3\%) patients. ST rates were higher in the LVEF moderate-severely impaired group compared with the normal LVEF group (2.8\% vs $2.1 \% ; \mathrm{HR} 1.82 ; \mathrm{Cl} 1.10$ to 3.00$)$. Especially early ST (EST) was more frequent in the moderate-severely impaired LVEF group (HR 2.20; CI 1.06 to 4.53). Overall rates of definite ST were lower in patients using EES compared with patients using SES or PES in all LVEF groups. Interaction terms were not statistically significant. ST rates were higher in the moderateseverely impaired LVEF group compared with the normal LVEF group when using SES or PES, but not significantly different when using EES.

Conclusions EES was associated with a lower risk of definite ST compared with early-generation DES. This lower risk was independent of LVEF, even though ST rates were higher in patients with a moderate-severely impaired LVEF.

Trial registration no MEC-2013-262.

\section{INTRODUCTION}

Early-generation drug-eluting stents (DES), sirolimus-eluting stents (SES) and paclitaxel-eluting stents (PES) appeared to be very effective at reducing the rates of restenosis and target lesion revascularisation compared with bare metal stents. ${ }^{1-4}$ However, stent thrombosis (ST), which causes acute coronary obstruction and could lead to myocardial infarction (MI) or sudden cardiac death, was found to be an infrequent but devastating complication of DES. Multiple randomised trials showed a comparable incidence of ST in DES compared with bare metal stents up to 1 year after the percutaneous coronary intervention (PCI). ${ }^{5-7}$ However, ST occurring more than 1 year after the index PCI, which is mainly caused by delayed healing in combination with other clinical and procedural risk factors of the stented coronary segment, ${ }^{8-11}$ appeared as a serious complication of DES stents. More recently, several randomised-controlled trials have shown a reduction in the incidence of ST occurring more than 1 year after the index PCI with newer-generation DES, releasing everolimus (ie, everolimus-eluting stents (EES)), ${ }^{12-14}$ which may have a favourable effect on cardiac death and incident MI. In these stents, everolimus, a sirolimus analogue, is released from a thin coating with more biocompatible polymers and reduced drug dose.

Several studies have identified impaired LV function as a risk factor for mortality, ${ }^{15-19} \mathrm{MI},{ }^{15}{ }_{17}$ $\mathrm{ST}^{17} 2021$ and target lesion revascularisation ${ }^{22}$ in patients undergoing PCI. It has been suggested that these patients may benefit from DES, ${ }^{22}$ especially since patients with impaired LVEF more frequently present with an acute coronary syndrome in case of in-stent restenosis. ${ }^{23}$ Since newer-generation EES stents seem to be superior to early-generation DES in an overall population of patients undergoing $\mathrm{PCI},{ }^{12-14}$ it would be useful to provide knowledge about the long-term safety and benefits of newergeneration EES in patients with a reduced cardiac function.

Against this background, we evaluated the longterm incidence of ST and clinical outcomes after PCI with DES in relation to LVEF in the Bern part of the Bern-Rotterdam registry. Second, we studied the performance of the newer-generation DES (EES) compared with the early-generation SES and PES in relation to LV function.

\section{METHODS}

Study design, patient population and procedures For the purpose of this study, we used the Bern (Bern University Hospital, Bern, Switzerland) part of the Bern-Rotterdam registry, which has been described before. ${ }^{12}$ We only used the Bern part of the registry since systematic data on the LVEF were not available in the Rotterdam part of the study population. The study population we used consisted of 5761 consecutive patients, who underwent
Windecker $S$, Umans VA et al. Heart 2015;101 50-57. 
PCI with PES, SES or EES, between April 2002 and March 2009. Between 16 April 2002 and 31 December 2005, a total of 2774 consecutive patients underwent coronary intervention with SES (Cypher, Cordis Corp, Johnson \& Johnson, Warren, New Jersey, USA) and 1365 were treated with PES (TAXUS, Express, or Liberté, Boston Scientific) in the Swiss centre. The individual use of both stent types has been described in detail elsewhere. ${ }^{24}$ A total of 1622 patients were treated with EES (XIENCE V, Abbott Vascular, Santa Clara, California, USA; or PROMUS, Boston Scientific, Natick, Massachusetts, USA), which has been part of the usual care since 1 November 2006 and implanted on a daily basis alternating with biolimus-eluting stents and zotarolimus-eluting stents. Patients with EES were included until 31 March 2009. Patients were excluded from the registry if more than one stent type was implanted during PCI. The nature of this study was observational and the procedure, periprocedural and postprocedural medication regimen, was performed according to current practice guidelines. The diameter of EES and PES was 2.25-4.0 mm, and the diameter of SES was $2.25-3.5 \mathrm{~mm}$. The length of all stents started at $8 \mathrm{~mm}$, with a maximum length of $28 \mathrm{~mm}$ of EES, $33 \mathrm{~mm}$ of SES and PES had a maximum length of $32 \mathrm{~mm}$. All patients received a loading dose of clopidogrel 300-600 mg during or immediately after PCI and a lifelong prescription of daily aspirin. Clopidogrel was prescribed for duration of at least 12 months. Glycoprotein IIb/IIIa antagonists were used at the discretion of the clinician.

The registry was approved by the local ethics committees and was conducted in accordance with the Declaration of Helsinki. Written informed consent was obtained from all patients.

\section{LV function}

Baseline LVEF was routinely assessed by LV angiography at the time of coronary angiography and determined by visual estimate. The visual estimate was performed by two experienced cardiologists. First by a fellow interventional cardiology, and this was subsequently verified or overruled by an attending senior invasive cardiologist. The estimate was based on the average of the right anterior oblique and left anterior oblique projection. Cineangiography was usually performed at 15 frames per second during injection of at least $30 \mathrm{~mL}$ contrast agent at a rate of $10 \mathrm{~mL}$ per second. Attention was paid to left ventricular size, overall contractility, any wall motion abnormalities and presence of mitral regurgitation. All senior invasive cardiologists perform yearly more than 500 coronary angiographies and the experience of a fellow interventional cardiology evolves over time. On average, a fellow interventional cardiology performs more than 800 cases in 1 year.

We divided patients into three different categories: (1) normal LVEF (>50\%), (2) mildly impaired LVEF $(>40-\leq 50 \%)$ or (3) moderate-severely impaired LVEF $(\leq 40 \%)$, which corresponds with generally accepted thresholds. ${ }^{15} 1925$ LVEF was available in $5446(94.5 \%)$ patients in the Swiss centre. Further analysis was performed only on patients with available LVEF.

\section{Study endpoints}

In Bern, follow-up lasted until 1 February 2007 in patients with SES or PES implantation and patients who received EES were followed up until 1 February 2010. Thus, the follow-up observation was up to 4 years in these subjects. Survival status was obtained from hospital records and municipal civil registries. Patients were actively followed up on adverse cardiac events by questionnaires that were sent to patients including questions on rehospitalisation and major adverse cardiac events. Medical records, discharge letters and coronary angiography documentation were collected and reviewed in patients with suspected events.

\section{Primary endpoint: definite ST}

Definite ST was the primary endpoint of our study, which was defined in agreement with the definitions of the Academic Research Consortium (ARC). ${ }^{26}$ We further classified the endpoint according to its timing (again in agreement with ARC): early ST (EST) (0-30 days after stent implantation) and late ST (LST) (>30 days). An independent clinical event committee adjudicated all suspect ST events. The committee members were not informed on the type of stent implanted.

\section{Secondary endpoints}

Secondary endpoints comprised adverse clinical events, including death from any cause, cardiac death, MI, as well as definite or probable ST.

Cardiac death was defined as any death from an immediate cardiac cause, procedure-related death, unwitnessed death and death with an unknown cause. MI was defined as increased creatine kinase $>2$ times the upper limit of the normal value and $>3$ times the upper limit of the normal value of creatine kinase-MB in combination with ischaemic changes on ECG. All suspect clinical events were adjudicated by the cardiologists who were affiliated with the institutions in which the patients were treated.

\section{Statistical analysis}

Categorical baseline and procedural variables are presented as counts and percentages, whereas differences between the three LVEF groups are evaluated by Pearson's $\chi^{2}$ test or Fisher's exact test, as appropriate. Continuous variables are presented as mean $\pm 1 \mathrm{SD}$, in case of a normal distribution, or as median, first and third quartiles, in case of a non-normal distribution. Differences between the LVEF groups were evaluated by applying analysis of variance, Student $t$ test, Kruskal-Wallis test and Mann-Whitney U test, as appropriate.

The incidence of the primary and secondary endpoints during follow-up in relation to LV function was evaluated according to the Kaplan-Meier method in combination with log-rank tests and by Cox proportional hazard regression analysis. Multivariable Cox models were developed to adjust the relation between LVEF and outcome for potential confounders. Baseline (clinical and procedural) characteristics that had a statistically significant $(\mathrm{p}<0.05)$ relation with the endpoint were entered into the model. No model reduction strategies were applied. We report adjusted HRs (aHRs) and their 95\% CIs. All events were only counted once.

Subsequently, we studied the relation between DES types and the study endpoints in relation to LV function. For this purpose, we used a method that our research group applied previously. ${ }^{12}$ We estimated propensity scores for receiving EES using a logit model that included age, sex and pretreatment variables associated with stent selection at $\mathrm{p}<0.10$ : family history of coronary artery disease, acute coronary syndrome, cardiogenic shock and body mass index. Propensity scores were used to derive the inverse probability of treatment weights, with the inverse of the propensity score as analytic weights in EES patients and the inverse of 1 minus the propensity score in early-generation DES patients. Comparisons between DES types were performed with the Cox model. Adjusted HRs were calculated with the inverse probability of treatment weights as analytical weighing factors. All Cox proportional hazard assumptions were visualised using 
the graph of the $\log (-\log ($ survival $))$ versus $\log$ of survival time graph and tested with Schoenfeld residuals. Interaction terms between LVEF and DES type were added to evaluate homogeneity of the effect of DES type on the study endpoints in relation to $\mathrm{LV}$ function.

\section{RESULTS}

A total of 5761 consecutive patients underwent PCI with PES (1365), SES (2774) or EES (1622) between 16 April 2002 and 31 March 2009. All analyses were performed on 5363 patients with PES (1298), SES (2599) or EES (1466) because LVEF was unavailable in 315 patients and 83 patients were lost to follow-up. Median follow-up was 2.4 years (IQR 1.9-3.0 years) in patients treated with EES, 3.6 years (IQR 2.8-4.0 years) in patients treated with SES and 4.0 years (IQR 3.4-4.0 years) in patients treated with PES.

\section{Baseline and procedural characteristics}

We observed several differences in clinical baseline and procedural characteristics between the three LVEF groups (table 1). Most notable were the differences in age, hypertension, body mass index, family history of coronary artery disease, smoking status, dyslipidemia and renal failure. Patients with a moderateseverely impaired or mildly impaired LVEF presented more often with an acute coronary syndrome $(74.7 \%$ and $74.0 \%$, respectively) than patients with a normal LVEF (41.1\%). Only patients with an impaired LV function presented with cardiogenic shock $(0.9 \%$ in the mildly impaired LVEF group and $5.8 \%$ in the moderate-severely impaired LVEF group).

Remarkable were the differences in number of patients undergoing multivessel treatment, stent diameter and length, number of stents implanted, use of glycoprotein IIb/IIIa and discharge medication. Normal LVEF patients more frequently had PES or SES implanted compared with more EES use in moderateseverely impaired LVEF patients. In the moderate-severely impaired LVEF group, the culprit vessel was more frequently the left main or left anterior descending artery, whereas relatively more normal LVEF patients culprit lesions in the left circumflex or right coronary artery. Baseline and procedural characteristics of all patients sorted by stent type are presented in the supplemental table.

\section{Study endpoints in relation to LV function}

The study endpoints are presented in table 2. Definite ST occurred in $123(2.3 \%)$ patients and definite/probable ST occurred in $331(6.2 \%)$ subjects. No patient had multiple STs. In general, patients with impaired LV function had a higher incidence of ST. In particular, patients with a moderate-severely impaired LVEF had a higher incidence of definite ST (aHR $1.82 ; 95 \%$ CI 1.10 to $3.00 ; \mathrm{p}$ value 0.02 ) and definite/probable ST (aHR 1.86; $95 \%$ CI 1.30 to 2.66 ; p value 0.001 ) than patients with a normal LVEF. This difference was based on higher EST rates in moderate-severely impaired LVEF patients (aHR 2.20; CI 1.06 to 4.53), whereas LST rates did not significantly differ (aHR 1.34; CI 0.72 to 2.50).

The incidence of clinical endpoints was also clearly associated with LV function. Specifically, more patients in the moderateseverely impaired LVEF group died (aHR 2.09; CI 1.60 to 2.73). A similar difference in clinical outcome was found in the incidence of cardiac death (aHR 2.58; CI 1.85 to 3.58). The occurrence of MI between was equal in the various LVEF groups.

\section{LV function, stent type and study endpoints}

Table 3 and figure 1 show the relationship between DES type and study endpoints. In general, patients who received EES had a lower incidence of ST than patients receiving PES or SES, although statistical significance could not be demonstrated for all endpoints. Differences between EES and PES were most pronounced. These observations were consistent in the three groups of patients according to LVEF. In particular, patients treated with EES had a lower incidence of definite ST than those treated with PES (aHRs 0.15, 0.13 and 0.12 for those with a normal, mildly impaired and moderate-severely impaired LVEF, respectively) and a lower incidence of definite/probable ST (aHRs 0.47, 0.65 and 0.52). Moderate-severely impaired LVEF patients had significantly higher rates of definite ST when using PES $(p=0.04)$ and a trend towards a higher incidence of ST when using SES $(p=0.07)$, whereas ST rates were similar in both LVEF groups when using EES $(p=0.34)$ (figure 2 ).

Most noteworthy concerning the differences in incidence of clinical endpoints between the DES types is the difference in the incidence of MI between patients treated with EES and those treated with PES (aHR 0.50, 0.65 and 0.19). The graph of the $\log (-\log ($ survival $))$ versus $\log$ of survival time graph resulted in parallel curves, and Schoenfeld residuals indicated Cox proportional hazard assumptions were not violated.

None of the LVEF * DES type interaction terms were significant in the multivariate analyses that we applied. Thus, we did not reveal any indication of heterogeneity in the relation between DES type and the study endpoints according to LV function.

\section{DISCUSSION}

This large observational cohort study with long-term follow-up of patients undergoing PCI with early-generation DES or newergeneration EES shows us that (1) impaired LV function was associated with increased risk of ST; (2) newer-generation EES was associated with a reduced risk of ST compared with earlygeneration DES; (3) the association between relative reduction of ST and EES was independent of LVEF and (4) EES seemed especially associated with reduced LST rates in patients with a normal LVEF, while the lower ST rates in the mildly impaired and moderate-severely impaired LVEF groups seemed unrelated to the timing of ST.

Our findings concerning the association between increased risk of ST and patients with impaired LV function are consistent with earlier findings. ${ }^{17} 2021$ Although the exact cause of the higher rate of ST in patients with reduced LV function remains unclear, it has been suggested that a decrease in LVEF is associated with impaired blood flow through the stented coronary artery, increasing the risk of $\mathrm{ST}^{27}$ In this study, the overall risk of ST in patients with impaired LVEF was increased by $61 \%$ compared with patients with a normal LVEF and by $13 \%$ compared with patients with a mildly impaired LVEF. Interestingly, a moderate-severely impaired LVEF did not seem to be associated with LST, but the difference in overall ST rates seems to be due to the strong association between the increased risk of having EST and a moderate-severely impaired LVEF compared with patients with a normal LVEF (a moderate-severely impaired LVEF was associated with a $120 \%$ increased risk of having EST). Sardi et al found an increase in the risk of ST with a HR of 2.56 (CI 1.44 to 4.55 ) when comparing patients with a LVEF of $25-40 \%$ to patients with a normal LVEF during 1-year follow-up, which is somewhat higher than the increase in the risk of ST we found in patients with a moderate-severely 
Table 1 Baseline and procedural characteristics

\begin{tabular}{|c|c|c|c|c|}
\hline Variable & Normal LVEF $(n=3106)$ & Mildly impaired LVEF ( $n=1244)$ & $\begin{array}{l}\text { Moderate-severely } \\
\text { impaired LVEF }(n=1013)\end{array}$ & $p$ Value \\
\hline Age (years) & $63.4 \pm 11.2$ & $62.5 \pm 12.2$ & $65.6 \pm 12.0$ & $<0.0001$ \\
\hline Male sex & $2343(75.4)$ & $982(78.9)$ & $759(74.9)$ & 0.03 \\
\hline BMI & $27.4 \pm 4.2$ & $27.3 \pm 4.3$ & $26.6 \pm 4.2$ & $<0.0001$ \\
\hline Hypertension & $1897(61.2)$ & $640(51.6)$ & $490(49.0)$ & $<0.0001$ \\
\hline Family history of CAD & $960(30.9)$ & $323(26.0)$ & $219(21.9)$ & $<0.0001$ \\
\hline Current smoking & $1646(53.1)$ & $666(53.7)$ & $466(46.6)$ & 0.0007 \\
\hline Dyslipidemia & $1827(58.9)$ & $609(49.1)$ & $444(44.4)$ & $<0.0001$ \\
\hline Diabetes mellitus & $529(17.1)$ & $203(16.4)$ & 195 (19.5) & 0.12 \\
\hline Renal failure (GFR<60 mL/min) & $291(12.1)$ & $107(12.0)$ & $180(21.8)$ & $<0.0001$ \\
\hline Acute coronary syndrome & $1276(41.1)$ & $921(74.0)$ & $757(74.7)$ & $<0.0001$ \\
\hline Unstable angina & $222(17.4)$ & $55(6.0)$ & $27(3.6)$ & \\
\hline Non-ST-segment-Elevation MI & $686(53.8)$ & $343(37.2)$ & $267(35.3)$ & \\
\hline ST-segment-elevation MI & $368(28.8)$ & $523(56.8)$ & $463(61.1)$ & \\
\hline Cardiogenic shock & 0 & $11(0.9)$ & $59(5.8)$ & $<0.0001$ \\
\hline Paclitaxel-eluting stent & $804(25.9)$ & $300(24.1)$ & $194(19.2)$ & $<0.0001$ \\
\hline Sirolimus-eluting stent & $1566(50.4)$ & $584(46.9)$ & $449(44.3)$ & 0.002 \\
\hline Everolimus-eluting stent & $736(23.7)$ & $360(28.9)$ & $370(36.5)$ & $<0.0001$ \\
\hline Multivessel treatment & $609(19.7)$ & $177(14.3)$ & 181 (17.9) & 0.0001 \\
\hline Lesions treated per patient & $1.6 \pm 0.8$ & $1.5 \pm 0.8$ & $1.6 \pm 0.9$ & 0.23 \\
\hline Culprit left main coronary artery & $59(1.8)$ & $22(1.8)$ & $62(6.1)$ & $<0.0001$ \\
\hline Arterial bypass graft & $8(0.3)$ & $2(0.2)$ & $3(0.3)$ & 0.78 \\
\hline Saphenous vein graft & $80(2.6)$ & $33(2.7)$ & $44(4.3)$ & 0.01 \\
\hline Multistent treatment & $1492(48.0)$ & $632(50.8)$ & $549(54.2)$ & 0.03 \\
\hline Average stent diameter & $2.9 \pm 0.6$ & $2.9 \pm 0.4$ & $3.0 \pm 0.4$ & 0.004 \\
\hline Total stent length per patient & $28.6 \pm 18.0$ & $30.8 \pm 18.1$ & $32.2 \pm 18.8$ & $<0.0001$ \\
\hline Glycoprotein IIb/llla antagonist & $441(14.2)$ & $390(31.4)$ & $353(34.8)$ & $<0.0001$ \\
\hline Aspirin at discharge & $3176(99.1)$ & $1225(98.5)$ & $963(95.1)$ & $<0.0001$ \\
\hline Clopidogrel at discharge & 3098 (99.7) & $1227(98.6)$ & $963(95.1)$ & $<0.0001$ \\
\hline Oral anticoagulation at discharge & $37(1.2)$ & $18(1.5)$ & $38(3.8)$ & $<0.0001$ \\
\hline
\end{tabular}

impaired LVEF of $\leq 40 \%$ at 1 year (HR 1.84; CI 1.01 to 3.34 ), but CIs are overlapping. ${ }^{17}$ Van Werkum et al also found considerably higher ST rates in patients with impaired systolic LV function (HR 2.27; CI 1.43 to 3.60), but they defined impaired cardiac function as LVEF $<30 \% .^{21}$ A LVEF $<30 \%$ is substantially lower than a LVEF $\leq 40 \%$. Since a poorer LVEF seems to increase the risk of ST, a higher HR in this study is in line with expectations.

Patients with a moderate-severely impaired LVEF treated with different kinds of DES also had higher all-cause mortality and

Table 2 Clinical outcomes

\begin{tabular}{|c|c|c|c|c|c|c|c|}
\hline \multirow[b]{2}{*}{ Variable } & \multirow[b]{2}{*}{$\begin{array}{l}\text { Normal LVEF } \\
(n=3106)\end{array}$} & \multirow[b]{2}{*}{$\begin{array}{l}\text { Mildly impaired } \\
\text { LVEF }(n=1244)\end{array}$} & \multirow[b]{2}{*}{$\begin{array}{l}\text { Moderate-severely } \\
\text { impaired VEF }(n=1013)\end{array}$} & \multicolumn{4}{|l|}{ Adjusted HR } \\
\hline & & & & $\begin{array}{l}\text { Mildly impaired } \\
\text { vs normal }\end{array}$ & p Value & $\begin{array}{l}\text { Moderate-severely } \\
\text { impaired vs normal }\end{array}$ & p Value \\
\hline Definite ST & $64(2.1)$ & $31(2.5)$ & $28(2.8)$ & $1.22(0.75-1.99)$ & 0.42 & $1.82(1.10-3.00)$ & 0.02 \\
\hline Early & $18(0.6)$ & $10(0.8)$ & $14(1.4)$ & $1.24(0.56-2.73)$ & 0.60 & $2.20(1.06-4.53)$ & 0.03 \\
\hline Late & $46(1.5)$ & $21(1.7)$ & $14(1.4)$ & $1.09(0.63-1.86)$ & 0.77 & $1.34(0.72-2.50)$ & 0.35 \\
\hline Definite/probable ST & $143(4.6)$ & $75(6.0)$ & $113(11.2)$ & $1.28(0.88-1.86)$ & 0.20 & $1.86(1.30-2.66)$ & 0.001 \\
\hline Early & $50(1.6)$ & $38(3.1)$ & $82(8.1)$ & $1.39(0.80-2.41)$ & 0.24 & $2.09(1.27-3.41)$ & 0.004 \\
\hline Late & $93(3.0)$ & $37(3.0)$ & $31(3.1)$ & $1.17(0.69-1.97)$ & 0.56 & $1.75(1.03-2.98)$ & 0.04 \\
\hline Death & $177(5.7)$ & 109 (8.8) & $194(19.2)$ & 1.46 (1.09-1.95) & 0.01 & $2.09(1.60-2.73)$ & $<0.0001$ \\
\hline Cardiac death & $104(3.4)$ & $82(6.6)$ & $150(14.8)$ & $1.88(1.32-2.66)$ & $<0.0001$ & $2.58(1.86-3.58)$ & $<0.0001$ \\
\hline MI & $138(4.4)$ & $53(4.2)$ & $49(4.8)$ & $1.05(0.76-1.45)$ & 0.77 & $1.37(0.98-1.92)$ & 0.07 \\
\hline
\end{tabular}


Table 3 Clinical outcomes sorted by drug-eluting stent type

\begin{tabular}{|c|c|c|c|c|c|c|c|c|}
\hline \multirow[b]{2}{*}{ Variable } & \multirow[b]{2}{*}{ LVEF group } & \multirow[b]{2}{*}{ EES } & \multirow[b]{2}{*}{ SES } & \multirow[b]{2}{*}{ PES } & \multicolumn{4}{|l|}{ Adjusted HR } \\
\hline & & & & & EES vs SES & $p$ Value & EES vs PES & p Value \\
\hline Overall definite ST & $\begin{array}{l}\text { Moderate-severely impaired } \\
\text { Mildly impaired } \\
\text { Normal }\end{array}$ & $\begin{array}{l}3(0.03) \\
1(0.01) \\
3(0.01)\end{array}$ & $\begin{array}{l}14(0.10) \\
22(0.10) \\
35(0.06)\end{array}$ & $\begin{array}{r}11(0.16) \\
8(0.07) \\
26(0.08)\end{array}$ & $\begin{array}{l}0.28(0.08-0.98) \\
0.11(0.02-0.78) \\
0.20(0.06-0.71)\end{array}$ & $\begin{array}{l}0.04 \\
0.03 \\
0.01\end{array}$ & $\begin{array}{l}0.15(0.04-0.55) \\
0.13(0.02-0.99) \\
0.12(0.03-0.44)\end{array}$ & $\begin{array}{l}0.004 \\
0.047 \\
0.001\end{array}$ \\
\hline Early definite ST & $\begin{array}{l}\text { Moderate-severely impaired } \\
\text { Mildly impaired } \\
\text { Normal }\end{array}$ & $\begin{array}{l}1(0.29) \\
1(0.28) \\
2(0.27)\end{array}$ & $\begin{array}{r}7(1.68) \\
5(0.88) \\
11(0.71)\end{array}$ & $\begin{array}{l}6(3.31) \\
4(1.37) \\
5(0.63)\end{array}$ & $\begin{array}{l}0.21(0.03-1.71) \\
0.44(0.05-3.75) \\
0.42(0.09-1.91)\end{array}$ & $\begin{array}{l}0.14 \\
0.45 \\
0.26\end{array}$ & $\begin{array}{l}0.11(0.01-0.89) \\
0.30(0.02-2.83) \\
0.67(0.09-2.34)\end{array}$ & $\begin{array}{l}0.04 \\
0.15 \\
0.35\end{array}$ \\
\hline Late definite ST & $\begin{array}{l}\text { Moderate-severely impaired } \\
\text { Mildly impaired } \\
\text { Normal }\end{array}$ & $\begin{array}{l}2(0.02) \\
0 \\
1(0.00)\end{array}$ & $\begin{array}{r}7(0.05) \\
17(0.08) \\
24(0.04)\end{array}$ & $\begin{array}{r}5(0.08) \\
4(0.03) \\
21(0.06)\end{array}$ & $\begin{array}{l}0.37(0.08-1.69) \\
\text { N.A. } \\
0.05(0.01-0.36)\end{array}$ & $\begin{array}{l}0.20 \\
\text { N.A. } \\
0.03\end{array}$ & $\begin{array}{l}0.21(0.04-1.07) \\
\text { N.A. } \\
0.02(0.00-0.18)\end{array}$ & $\begin{array}{l}0.06 \\
\text { N.A. } \\
<0.0001\end{array}$ \\
\hline Overall definite/probable ST & $\begin{array}{l}\text { Moderate-severely impaired } \\
\text { Mildly impaired } \\
\text { Normal }\end{array}$ & $\begin{array}{l}31(0.31) \\
15(0.15) \\
19(0.09)\end{array}$ & $\begin{array}{l}53(0.37) \\
38(0.18) \\
77(0.13)\end{array}$ & $\begin{array}{l}29(0.44) \\
22(0.18) \\
47(0.14)\end{array}$ & $\begin{array}{l}0.70(0.45-1.09) \\
0.67(0.36-1.25) \\
0.73(0.44-1.20)\end{array}$ & $\begin{array}{l}0.12 \\
0.21 \\
0.21\end{array}$ & $\begin{array}{l}0.52(0.31-0.88) \\
0.65(0.33-1.30) \\
0.47(0.27-0.81)\end{array}$ & $\begin{array}{c}0.02 \\
0.22 \\
0.01\end{array}$ \\
\hline Early definite/probable ST & $\begin{array}{l}\text { Moderate-severely impaired } \\
\text { Mildly impaired } \\
\text { Normal }\end{array}$ & $\begin{array}{l}26(7.49) \\
11(3.14) \\
12(1.65)\end{array}$ & $\begin{array}{l}38(9.14) \\
16(2.81) \\
23(1.49)\end{array}$ & $\begin{array}{l}18(9.94) \\
11(3.79) \\
15(1.90)\end{array}$ & $\begin{array}{l}0.77(0.47-1.28) \\
1.00(0.45-2.21) \\
1.18(0.58-2.38)\end{array}$ & $\begin{array}{l}0.32 \\
0.99 \\
0.65\end{array}$ & $\begin{array}{l}0.73(0.40-1.33) \\
0.71(0.29-1.72) \\
0.89(0.41-1.90)\end{array}$ & $\begin{array}{l}0.30 \\
0.44 \\
0.75\end{array}$ \\
\hline Late definite/probable ST & $\begin{array}{l}\text { Moderate-severely impaired } \\
\text { Mildly impaired } \\
\text { Normal }\end{array}$ & $\begin{array}{l}5(0.05) \\
4(0.04) \\
7(0.03)\end{array}$ & $\begin{array}{l}15(0.11) \\
22(0.11) \\
54(0.09)\end{array}$ & $\begin{array}{l}11(0.17) \\
11(0.09) \\
32(0.10)\end{array}$ & $\begin{array}{l}0.48(0.17-1.33) \\
0.41(0.13-1.23) \\
0.45(0.20-.0 .98)\end{array}$ & $\begin{array}{l}0.16 \\
0.11 \\
0.045\end{array}$ & $\begin{array}{l}0.22(0.07-0.71) \\
0.58(0.19-1.78) \\
0.26(0.11-0.61)\end{array}$ & $\begin{array}{l}0.01 \\
0.34 \\
0.002\end{array}$ \\
\hline Death & $\begin{array}{l}\text { Moderate-severely impaired } \\
\text { Mildly impaired } \\
\text { Normal }\end{array}$ & $\begin{array}{l}59(0.59) \\
27(0.26) \\
28(0.13)\end{array}$ & $\begin{array}{l}92(0.61) \\
50(0.23) \\
91(0.15)\end{array}$ & $\begin{array}{l}43(0.61) \\
32(0.26) \\
58(0.17)\end{array}$ & $\begin{array}{l}0.81(0.58-1.13) \\
1.01(0.61-1.67) \\
0.84(0.55-1.28)\end{array}$ & $\begin{array}{l}0.22 \\
0.96 \\
0.42\end{array}$ & $\begin{array}{l}0.78(0.52-1.18) \\
0.93(0.53-1.62) \\
0.71(0.45-1.11)\end{array}$ & $\begin{array}{l}0.24 \\
0.80 \\
0.13\end{array}$ \\
\hline Cardiac death & $\begin{array}{l}\text { Moderate-severely impaired } \\
\text { Mildly impaired } \\
\text { Normal }\end{array}$ & $\begin{array}{l}47(0.47) \\
21(0.20) \\
16(0.07)\end{array}$ & $\begin{array}{l}68(0.45) \\
35(0.16) \\
50(0.08)\end{array}$ & $\begin{array}{l}35(0.49) \\
26(0.21) \\
38(0.11)\end{array}$ & $\begin{array}{l}0.85(0.58-1.25) \\
1.12(0.64-1.98) \\
0.85(0.49-1.49)\end{array}$ & $\begin{array}{l}0.42 \\
0.69 \\
0.57\end{array}$ & $\begin{array}{l}0.75(0.48-1.18) \\
0.83(0.45-4.53) \\
0.62(0.35-1.11)\end{array}$ & $\begin{array}{l}0.21 \\
0.55 \\
0.11\end{array}$ \\
\hline Ml & $\begin{array}{l}\text { Moderate-severely impaired } \\
\text { Mildly impaired } \\
\text { Normal }\end{array}$ & $\begin{array}{r}6(0.06) \\
11(0.11) \\
19(0.09)\end{array}$ & $\begin{array}{l}27(0.19) \\
25(0.12) \\
74(0.12)\end{array}$ & $\begin{array}{l}16(0.24) \\
17(0.14) \\
45(0.14)\end{array}$ & $\begin{array}{l}0.29(0.12-0.70) \\
0.65(0.35-1.57) \\
0.77(0.47-1.29)\end{array}$ & $\begin{array}{l}0.01 \\
0.44 \\
0.32\end{array}$ & $\begin{array}{l}0.19(0.07-0.54) \\
0.65(0.29-1.43) \\
0.50(0.29-0.87)\end{array}$ & $\begin{array}{l}0.002 \\
0.28 \\
0.01\end{array}$ \\
\hline
\end{tabular}

Clinical outcome numbers are expressed as counts (number of events/month/100 patients). Adjusted risk ratios were calculated with the inverse probability of treatment weights as analytical weighting in Cox proportional hazards models.

EES, everolimus-eluting stent; MI, myocardial infarction; PES, paclitaxel-eluting stent; SES, sirolimus-eluting stent; ST, stent thrombosis.

cardiac mortality risk compared with normal LVEF patients. A trend towards a higher risk of MI was found in patients with a moderate-severely impaired LVEF. Our findings regarding the relationship between a reduced LVEF and the increased mortality, ${ }^{15-18}$ and risk of MI, ${ }^{15}{ }^{17}$ are also consistent with earlier findings. Mortality and cardiac mortality seem to increase as LVEF drops. In the moderate-severely impaired LVEF group, overall 1-year mortality was $11.8 \%$ and $11.3 \%$ in patients who had EES implanted. The 1-year mortality rates in this group are comparable to earlier findings. ${ }^{15} 17$ Patients with a mildly impaired LVEF and normal LVEF showed 1-year mortality rates of $4.4 \%$ and $1.8 \%$, respectively.

This is the first study that specifically compared the outcome of early-generation DES stents, SES and PES, compared with newer-generation EES in patients with a varying systolic cardiac function, in a registry with long-term follow-up observation to 4 years. This registry has the advantage that it consists of consecutive patients, has long-term follow-up and is not a post hoc analysis of a large randomised-controlled trial, which apply specific inclusion criteria that complicates extrapolation of their results to the more diverse, real-life population of patients.

The study shows that EES is associated with lower ST rates compared with early-generation DES, irrespective of LV function. Interestingly, when comparing the difference in definite overall ST rates between patients with a moderate-severely impaired LVEF versus normal LVEF per stent, we found statistically higher ST rates in patients using PES and a trend towards higher ST rates when using SES, but no differences in the incidence of ST when found using EES. On the other hand, we found no interaction when comparing EES to early-generation DES in various LVEF groups. It could be possible that the event rate in our study population of patients using EES was too low to show interaction. Another explanation could be the fact that a moderate-severely impaired LVEF seemed to be especially associated with increased risk of EST, whereas EES, a sirolimus derivate, with more biocompatible polymers and reduced drug dose, seemed predominantly associated with lower LST and very late ST rates compared with early-generation DES. ${ }^{12-14}$ Although EES also seems superior in preventing EST compared with early-generation DES. ${ }^{12} 13$

The findings of this study can be used in clinical practice when performing a PCI in patients with systolic dysfunction. The study emphasises the known fact that EES is superior to earlygeneration DES, but also shows that whether systolic dysfunction is present or not, EES remains superior even after 4 years. When performing PCI on patients with a reduced LVEF, the executive physician should keep in mind that these patients have higher ST rates, in particular EST, higher incidence of MI and higher mortality rates. Despite these improved lower ST rates achieved by using EES, more efforts and research to improve ST and mortality rates is mandated to improve the outcome of patients with a reduced systolic cardiac function undergoing PCI.

\section{Limitations}

Several issues concerning this study warrant further consideration. First of all, the ST event rate was quite low, especially in EES patients. This low event rate may have caused a lack of power to show significant differences.

The use of LVEF, which was performed angiographically, using biplane assessment by visual estimate, is inherently an issue since reproducibility of this method may be questioned. To accommodate this limitation, we divided all study patients in 
Figure 1 Kaplan-Meier hazard curve of overall definite stent thrombosisoverall definite stent thrombosis in patients using different drug-eluting stents of patients with a $(A)$ moderate-severely impaired LVEF, (B) mildly impaired LVEF and (C) normal LVEF.
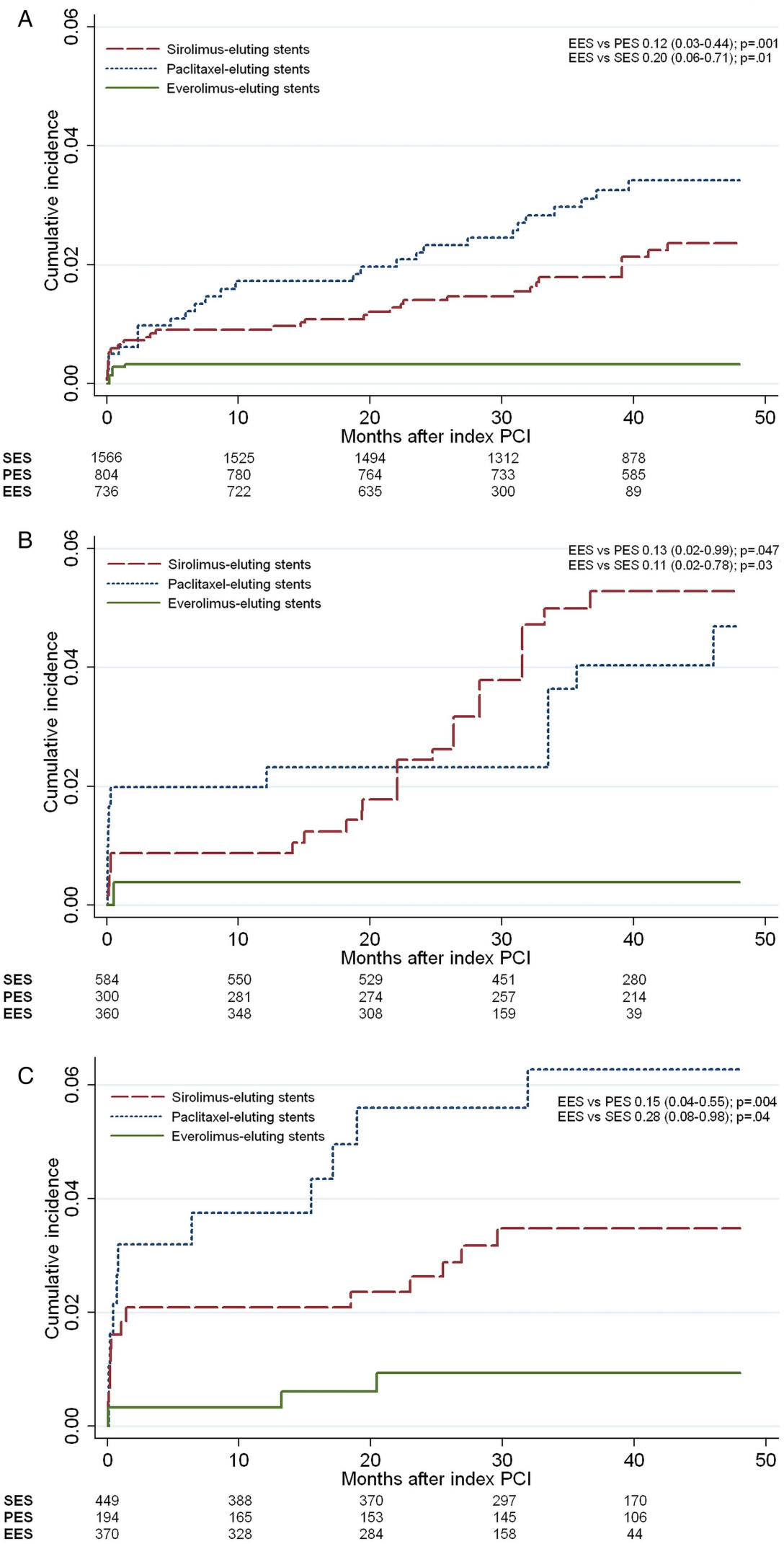

three different LVEF categories to reduce the effect of measurement discrepancies in LVEF assessment.

Furthermore, there were differences in baseline characteristics between patients who had been stented with EES, SES and PES after PCI and no randomisation was performed.
These differences in baseline characteristics had to be adjusted for using the inverse probability of treatment weighting, as we did before, ${ }^{12}$ to minimise a potential bias. Also, follow-up at 4 years was not complete in patients treated with EES and PES. 

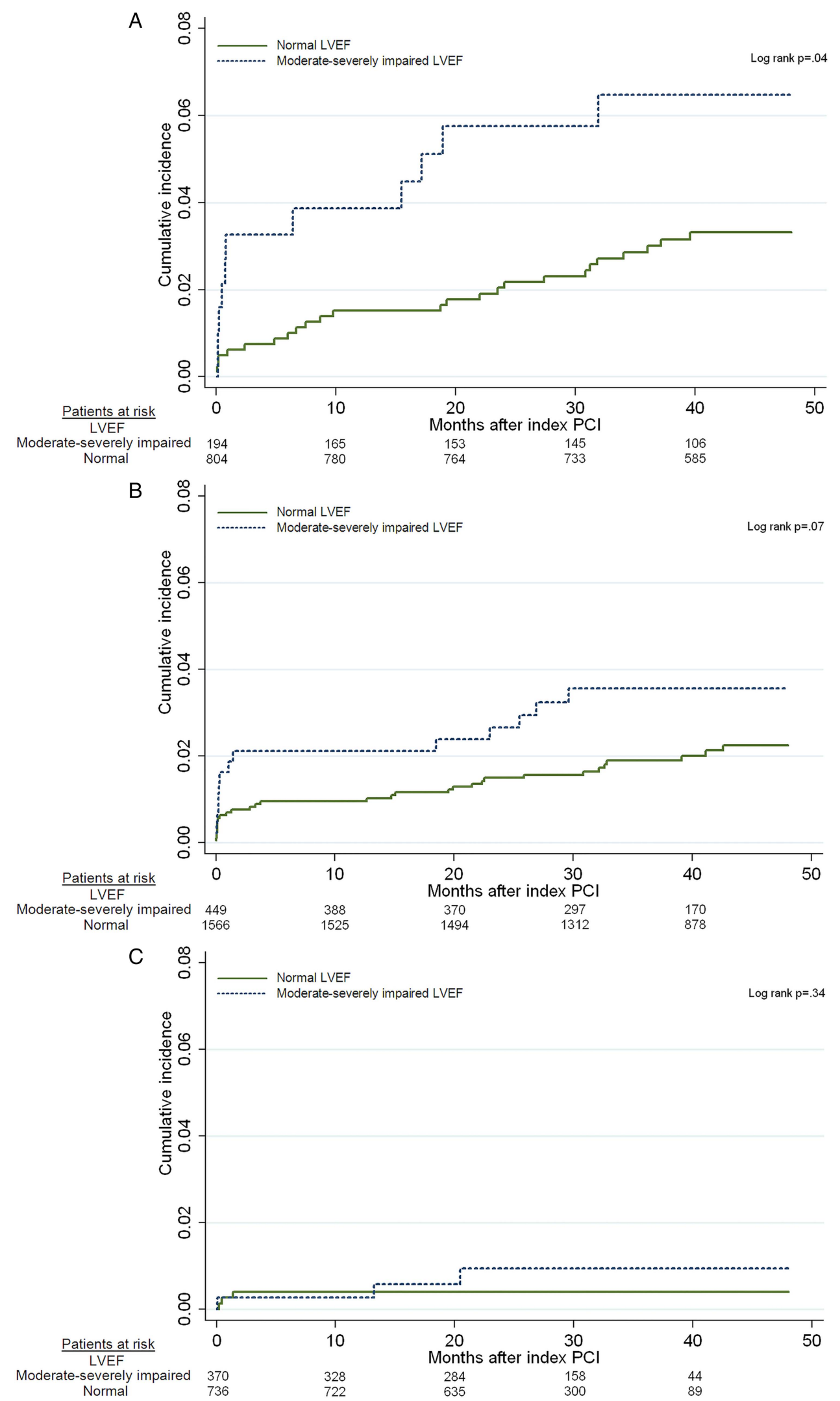

Figure 2 Kaplan-Meier hazard curve of overall definite stent thrombosis—overall definite stent thrombosis in patients with a moderate-severely impaired vs normal LVEF of patients with (A) paclitaxel-eluting stents, (B) sirolimus-eluting stents and (C) everolimus-eluting stents.

Another issue that should be taken into account is the fact that a primary arrhythmia causing death within 30 days would full the ARC criteria for probable $\mathrm{ST}^{26}$ which withholds us from distinguishing between sudden death due to ST and a primary arrhythmia. This may consequently have influenced our results. 
PCI strategies have improved over time, which may have contributed to an improved outcome among patients with EES, compared with patients with early-generation DES.

Other limitations of this study are related to the database, and these limitations have been reported before. ${ }^{12}$

\section{CONCLUSION}

Newer-generation EES was associated with a reduced risk of ST compared with early-generation DES, even after long-term follow-up of up to 4 years, regardless of LVEF. The relative reduction found was independent of LVEF, even though ST rates were higher in patients with a moderate-severely impaired LVEF. This association between reduced ST rates and a normal LVEF using EES was predominantly based on lower LST rates, whereas the lower occurrence of ST achieved by EES in patients with a reduced LVEF seemed unrelated to the timing of ST. Finally, all-cause mortality and cardiac mortality rates seem to be inversely related to LV function.

\section{Key messages}

\section{What is already known on this subject?}

Drug-eluting stents (DES), sirolimus-eluting stents (SES) and paclitaxel-eluting stents (PES) reduce the rates of restenosis and target lesion revascularisation compared with bare metal stents. Stent thrombosis (ST), especially late ST, is an infrequent complication of DES. Newer-generation DES, releasing everolimus (ie, everolimus-eluting stents (EES)), have shown reduced (late) ST rates after percutaneous coronary intervention (PCI). Additionally, an impaired LVEF is a risk factor for ST.

\section{What might this study add?}

The current study shows that newer-generation EES was associated with a lower risk of ST compared with early-generation DES, even after follow-up of up to 4 years. The relative reduction of ST found was independent of LVEF, even though ST rates were higher in patients with a moderateseverely impaired LVEF.

\section{How might this impact on clinical practice?}

In our study, EES was associated with lower ST rates compared with older-generation DES, whether or not a patient has systolic dysfunction. The knowledge provided about the long-term safety and benefits of newer-generation EES in patients with a reduced cardiac function may suggest that EES should be the preferred stent when performing a $\mathrm{PCl}$ in patients with systolic dysfunction.

Contributors $\mathrm{NvB}$ is the main writer of the article and contributed to the analysis and interpretation of data, revision of the article and gave final approval of the version to be published. SW, RTVD, R-JvG, PWS, MM and LR contributed to the data collection and design of the paper and revised the article. Final approval of the version to be published was given by all authors. VAU, IK, KMA and EB contributed to analysis and interpretation of data, revised the article critically for important intellectual content and gave final approval of the version to be published.

Competing interests SW has received research contracts to the institution from Abbott, Boston Scientific, Biosensors, Cordis, Biotronik, St. Jude and Medtronic.

Patient consent Obtained.

Ethics approval The registry was approved by the local ethics committees, and was conducted in accordance with the Declaration of Helsinki.

Provenance and peer review Not commissioned; externally peer reviewed.

\section{REFERENCES}

1 Stone GW, Ellis SG, Cox DA, et al. A polymer-based, paclitaxel-eluting stent in patients with coronary artery disease. N Engl J Med 2004;350:221-31.

2 Stone GW, Ellis SG, Cannon L, et al. Comparison of a polymer-based paclitaxel-eluting stent with a bare metal stent in patients with complex coronary artery disease: a randomized controlled trial. JAMA 2005;294:1215-23.

3 Moses JW, Leon MB, Popma JJ, et al. Sirolimus-eluting stents versus standard stents in patients with stenosis in a native coronary artery. $N$ Engl J Med 2003;349:1315-23.

4 Morice MC, Serruys PW, Sousa JE, et al. A randomized comparison of a sirolimus-eluting stent with a standard stent for coronary revascularization. $N$ Eng/ J Med 2002;346:1773-80

5 Kastrati A, Mehilli J, Pache J, et al. Analysis of 14 trials comparing sirolimus-eluting stents with bare-metal stents. N Engl J Med 2007;356:1030-9.

6 Stettler C, Wandel S, Allemann S, et al. Outcomes associated with drug-eluting and bare-metal stents: a collaborative network meta-analysis. Lancet 2007;370: 937-48.

7 Stone GW, Moses JW, Ellis SG, et al. Safety and efficacy of sirolimus- and paclitaxel-eluting coronary stents. N Engl J Med 2007;356:998-1008.

8 Joner M, Finn AV, Farb A, et al. Pathology of drug-eluting stents in humans: delayed healing and late thrombotic risk. J Am Coll Cardiol 2006;48:193-202.

9 Cook S, Wenaweser P, Togni M, et al. Incomplete stent apposition and very late stent thrombosis after drug-eluting stent implantation. Circulation 2007; 115:2426-34

10 Nakazawa G, Finn AV, Joner M, et al. Delayed arterial healing and increased late stent thrombosis at culprit sites after drug-eluting stent placement for acute myocardial infarction patients: an autopsy study. Circulation 2008;118: $1138-45$

11 Hassan AK, Bergheanu SC, Stijnen T, et al. Late stent malapposition risk is higher after drug-eluting stent compared with bare-metal stent implantation and associates with late stent thrombosis. Eur Heart J 2010;31:1172-80.

12 Raber L, Magro M, Stefanini GG, et al. Very late coronary stent thrombosis of a newer-generation everolimus-eluting stent compared with early-generation drug-eluting stents: a prospective cohort study. Circulation 2012;125: 1110-21.

13 Kedhi E, Joesoef KS, McFadden E, et al. Second-generation everolimus-eluting and paclitaxel-eluting stents in real-life practice (COMPARE): a randomised trial. Lancet 2010;375:201-9.

14 Stone GW, Rizvi A, Newman W, et al. Everolimus-eluting versus paclitaxel-eluting stents in coronary artery disease. N Engl J Med 2010;362:1663-74.

15 Keelan PC, Johnston JM, Koru-Sengul T, et al. Comparison of in-hospital and one-year outcomes in patients with left ventricular ejection fractions $<0 r=40 \%$, $41 \%$ to $49 \%$, and $>0 \mathrm{r}=50 \%$ having percutaneous coronary revascularization. $\mathrm{Am} \mathrm{J}$ Cardiol 2003;91:1168-72

16 Wallace TW, Berger JS, Wang A, et al. Impact of left ventricular dysfunction on hospital mortality among patients undergoing elective percutaneous coronary intervention. Am J Cardiol 2009:103:355-60

17 Sardi GL, Gaglia MA Jr, Maluenda G, et al. Outcome of percutaneous coronary intervention utilizing drug-eluting stents in patients with reduced left ventricular ejection fraction. Am J Cardiol 2012;109:344-51.

18 de la Torre-Hernandez JM, Alfonso F, Hernandez F, et al. Drug-eluting stent thrombosis: results from the multicenter Spanish registry ESTROFA (Estudio ESpanol sobre TROmbosis de stents FArmacoactivos). J Am Coll Cardiol 2008;51: 986-90.

19 Cayla G, Hulot JS, O'Connor SA, et al. Clinical, angiographic, and genetic factors associated with early coronary stent thrombosis. JAMA 2011;306:1765-74.

20 lakovou I, Schmidt T, Bonizzoni E, et al. Incidence, predictors, and outcome of thrombosis after successful implantation of drug-eluting stents. JAMA 2005:293:2126-30.

21 van Werkum JW, Heestermans AA, Zomer AC, et al. Predictors of coronary stent thrombosis: the Dutch Stent Thrombosis Registry. J Am Coll Cardiol 2009;53:1399-409.

22 Biondi ZG, Moretti C, Abbate A, et al. Percutaneous coronary stenting in patients with left ventricular systolic dysfunction: a systematic review and meta-analysis. Eurolntervention. 2007:3:409-15.

23 Chen MS, John JM, Chew DP, et al. Bare metal stent restenosis is not a benign clinical entity. Am Heart J 2006;151:1260-4.

24 Daemen J, Wenaweser P, Tsuchida K, et al. Early and late coronary stent thrombosis of sirolimus-eluting and paclitaxel-eluting stents in routine clinical practice: data from a large two-institutional cohort study. Lancet 2007;369:667-78.

25 Aslam F, Blankenship JC. Coronary artery stenting in patients with severe left ventricular dysfunction. J Invasive Cardiol 2005;17:656-8.

26 Cutlip DE, Windecker $S$, Mehran $R$, et al. Clinical end points in coronary stent trials: a case for standardized definitions. Circulation 2007;115:2344-51.

27 Nusca A, Lipinski MJ, Varma A, et al. Safety of drug-eluting stents in patients with left ventricular dysfunction undergoing percutaneous coronary intervention. $\mathrm{Am} J$ Cardiol 2008;102:679-82. 